Revista Eletrônica de Direito Processual - REDP.

Rio de Janeiro. Ano 12. Volume 19. Número 1. Janeiro a Abril de 2018

Periódico Quadrimestral da Pós-Graduação Stricto Sensu em Direito Processual da UERJ

Patrono: José Carlos Barbosa Moreira (in mem.). ISSN 1982-7636. pp. 83-106

www.redp.uerj.br

\title{
NEOINSTRUMENTALISMO DO PROCESSO? - EXPANSÃO DOS MÉTODOS ATÍPICOS DE RESOLUÇÕES DE CONFLITOS ${ }^{1}$
}

\section{NEOINSTRUMENTALISM OF THE PROCESS? - EXPANSION OF ATYPICAL METHODS OF CONFLICT RESOLUTIONS}

Eduardo Cambi

Pós-doutor em Direito pela Università degli Studi di Pavia (Itália). Doutor e Mestre em Direito pela Universidade Federal do Paraná (UFPR). Professor da Universidade Estadual do Norte do Paraná (UENP) e da Universidade Paranaense (UNIPAR). Promotor de Justiça no Paraná. Coordenador do Centro de Estudos e Aperfeiçoamento Funcional (CEAF) do Ministério Público do Paraná. Curitiba, Paraná, Brasil. E-mail: eduardocambi@hotmail.com

Eluane de Lima Corrales Mestranda do Programa de Pós-Graduação em Ciência Jurídica da Universidade Estadual do Norte do Paraná (UENP). Pós - graduanda em Direito Público pela Universidade Estácio de Sá. Bacharela em Direito pela Universidade Estadual do Norte do Paraná (UENP). Advogada. Ribeirão do Pinhal, Paraná, Brasil. E-mail: eluanecorrales@hotmail.com

RESUMO: O presente artigo pretende examinar os diversos meios alternativos de resolução de conflitos à luz do Neoconstitucionalismo e do Neoprocessualismo. A problemática reside no questionamento: como o Neoconstitucionalismo e $\mathrm{o}$ Neoprocessualismo contribuíram para o maior acesso à justiça e à maior efetividade na resolução de conflitos? A pesquisa foi desenvolvida a partir do método de abordagem

\footnotetext{
${ }^{1}$ Artigo recebido em 03/01/2018 e aprovado em 01/04/2018.
} 
Revista Eletrônica de Direito Processual - REDP.

Rio de Janeiro. Ano 12. Volume 19. Número 1. Janeiro a Abril de 2018

Periódico Quadrimestral da Pós-Graduação Stricto Sensu em Direito Processual da UERJ

Patrono: José Carlos Barbosa Moreira (in mem.). ISSN 1982-7636. pp. 83-106

www.redp.uerj.br

qualitativo, com método de procedimento bibliográfico. Foram analisados aspectos

históricos e as principais características do Neoconstitucionalismo e Neoprocessualismo, bem como suas influências sobre os meios alternativos de resoluções de conflitos. Em seguida, são estudadas a mediação, conciliação, arbitragem, justiça restaurativa e as constelações sistêmicas.

PALAVRAS-CHAVE: Neoconstitucionalismo. Neoprocessualismo.

Neoinstrumentalismo. Justiça Restaurativa. Constelações Sistêmicas.

ABSTRACT: The present article has as its scope the analysis of the various alternative means of conflict resolution in the light of Neoconstitutionalism and Neoprocessalism. The problem lies in the questioning: how did neo-constitutionalism and neoprocessualism contribute to greater access to justice and greater effectiveness in resolving conflicts? The research was developed from the method of qualitative approach, with method of bibliographic procedure. The historical aspects and main characteristics of Neoconstitutionalism and Neoprocessalism were analyzed, as well as their influence on alternative means of conflict resolution. Next, the alternative methods that are most prominent in Brazil were presented, being mediation, conciliation, arbitration, restorative justice and systemic constellations.

KEYWORDS: Neoconstitutionalism. Neoprocessualism. Neoinstrumentalism. Restorative Justice. Systemic Constellations.

SUMÁRIO: 1. Introdução; 2. Considerações sobre o Neoconstitucionalismo; 3. Considerações sobre o Neoprocessualismo; 4. Neoprocessualismo e métodos alternativos de resolução de conflitos: Neoinstrumentalismo?; Conclusão; Referências bibliográficas.

\section{INTRODUÇÃO}

O atual contexto social e jurídico é resultante de um longo desenvolvimento histórico. Não se pode ignorar o passado para se compreender o presente e aperfeiçoar os 
Revista Eletrônica de Direito Processual - REDP.

Rio de Janeiro. Ano 12. Volume 19. Número 1. Janeiro a Abril de 2018

Periódico Quadrimestral da Pós-Graduação Stricto Sensu em Direito Processual da UERJ

Patrono: José Carlos Barbosa Moreira (in mem.). ISSN 1982-7636. pp. 83-106

www.redp.uerj.br

institutos jurídicos para o futuro. O mundo está em constante transformação e o direito deve acompanhar as mudanças para não perder contato com a realidade social.

Com o advento do Neoconstitucionalismo novas formas de ver e aplicar o Direito foram adotadas, as quais são essenciais para a realização da justiça. Princípios foram reconhecidos como normas jurídicas e foram cada vez mais utilizados como formas de proteção e persecução das garantias constitucionais.

O Neoprocessualismo também busca maior efetividade para o direito processual por meio da concretização de princípios como o do acesso à justiça, da dignidade da pessoa humana e da duração razoável do processo, os quais servem para promover os novos métodos de resoluções de conflitos.

O presente artigo possui como escopo a análise de como o Neoconstitucionalismo e o Neoprocessualismo podem estimular a cultura da paz, contribuindo para o acesso a uma ordem jurídica justa e com maior efetividade na resolução de conflitos ${ }^{2}$. Nesse contexto, pode-se questionar: é possível, a partir dessas categorias, pensar na Neoinstrumentalidade do processo?

A pesquisa foi desenvolvida a partir do método de abordagem qualitativo, com análise do procedimento bibliográfico. De início, foram abordados os principais aspectos e características do Neoconstitucionalismo. Em seguida, tratou-se do Neoprocessualismo e dos novos métodos alternativos de resoluções de conflitos, com destaque para a mediação, a conciliação, a arbitragem, a justiça restaurativa e as constelações sistêmicas.

\section{CONSIDERAÇÕES SOBRE O NEOCONSTITUCIONALISMO}

O Neoconstitucionalismo é um novo método de compreensão do Direito Constitucional, estando voltado para a realização do Estado Democrático de Direito, por meio da real efetivação dos diversos direitos e garantias fundamentais. É pautado no caráter transformador existente nas Constituições modernas, as quais são frequentemente denominadas como utopias de direito positivo. Porém, é tal caráter transformador que atua

\footnotetext{
${ }^{2}$ CAMBI, Eduardo; DOTTI, Rogéria; PINHEIRO, Paulo Eduardo d’Arce; MARTINS; KOZIKOSKI, Sandro Marcelo. Curso de Processo Civil Completo. São Paulo: RT, 2017, p. 393.
} 
Revista Eletrônica de Direito Processual - REDP.

Rio de Janeiro. Ano 12. Volume 19. Número 1. Janeiro a Abril de 2018

Periódico Quadrimestral da Pós-Graduação Stricto Sensu em Direito Processual da UERJ

Patrono: José Carlos Barbosa Moreira (in mem.). ISSN 1982-7636. pp. 83-106

www.redp.uerj.br

como o grande orientador para a realização das necessárias mudanças sociais ${ }^{3}$. Sobretudo,

deve-se levar em conta que o Neoconstitucionalismo não pode ser visto como um método

fixo e imutável, mas sim como um movimento para a transformação do Direito em termos de qualidade, utilizando-se para tanto, da força normativa da Constituição, bem como da sua utilização como um marco referencial para todos os ordenamentos jurídicos ${ }^{4}$.

O Neoconstitucionalismo pode ser compreendido a partir dos marcos histórico, filosófico e jurídico. O marco histórico é pautado na formação do Estado Constitucional de Direito; o filosófico, no pós-positivismo, também chamado de Neopositivismo, com a centralidade dos direitos fundamentais e a reaproximação ente o Direito e o que é ético.

Já o marco jurídico pode ser considerado como o conjunto de mudanças que incluem a força normativa da Constituição, a expansão da jurisdição constitucional e o desenvolvimento de uma nova dogmática de interpretação constitucional ${ }^{5}$.

A partir da perspectiva histórica, o Neoconstitucionalismo pode ser compreendido como um novo paradigma surgido após a II Guerra Mundial, tendo origem na Alemanha com a Lei Fundamental de Bonn, em 1949 e a instalação do Tribunal Constitucional Federal, em 1951. Na Itália, teve origem com a nova Constituição de 1947 e sua Corte Constitucional, de 1956. Tais providências foram implementadas como respostas aos movimentos nazistas e fascistas que existiram nesses países ${ }^{6}$.

Diversos países aderiram ao movimento neoconstitucionalista anos mais tarde, incluindo o Brasil, o qual possui como marco a Constituição Federal de 1988, a qual marca a transição para o Estado Democrático de Direito, sendo promulgada logo após a queda do regime ditatorial.

O neoconstitucionalismo surge como uma decorrência da sociedade do século XVIII, baseado na necessidade de assegurar maior segurança jurídica, bem como evitar o arbítrio estatal. O advento da II Guerra Mundial e demais transformações ocorridas em

\footnotetext{
${ }^{3}$ CAMBI, Eduardo. Neoconstitucionalismo e neoprocessualismo: direitos fundamentais, políticas públicas e protagonismo judiciário. São Paulo: Almedina, 2016, p. 28.

${ }^{4}$ MÖLLER, Max. Teoria Geral do neoconstitucionalismo: bases teóricas do constitucionalismo contemporâneo. Porto Alegre: Livraria do Advogado, 2011, p. 15.

${ }^{5}$ BARROSO, Luís Roberto. Neoconstitucionalismo e Constitucionalização do Direito: O triunfo tardio do direito constitucional no Brasil. 26. abr. 2006. Disponível em: < https://www.conjur.com.br/2006-abr26/triunfo_tardio_direito_constitucional_brasil>.Acesso em 12. out. 2017, p. 3-6.

${ }^{6}$ FILIPPO, Thiago Baldani Gomes De. Neoconstitucionalismo e súmulas vinculantes. Porto Alegre: Sergio Antonio Fabris Ed., 2012, p. 57.
} 
Revista Eletrônica de Direito Processual - REDP.

Rio de Janeiro. Ano 12. Volume 19. Número 1. Janeiro a Abril de 2018

Periódico Quadrimestral da Pós-Graduação Stricto Sensu em Direito Processual da UERJ

Patrono: José Carlos Barbosa Moreira (in mem.). ISSN 1982-7636. pp. 83-106

www.redp.uerj.br

meados do século passado acentuaram a necessidade de limitar o poder do Estado e assegurar direitos e garantias fundamentais aos cidadãos.

Salienta-se que a expressão "neo" permite que mudanças paradigmáticas chamem a atenção dos operadores do direito, proporcionando que temas e transformações relevantes possuam espaço nas discussões doutrinárias, bem como na aplicação desses novos paradigmas. Tal expressão revela que é necessário que se realize um ajuste entre a nova realidade apresentada e o Direito, sobretudo por meio da hermenêutica, ou ainda com a apresentação de novas e melhores soluções para os velhos problemas ${ }^{7}$.

Ressalta-se que o termo "Neoconstitucionalismo" pode possuir diversos sentidos tendo em vista os aspectos teórico, ideológico e metodológico ${ }^{8}$. Do ponto de vista teórico, pode ser visto como a busca pela constitucionalização dos ordenamentos jurídicos, representando uma alternativa e marcando a superação ao jusnaturalismo e ao positivismo jurídico 9 .

O Neoconstitucionalismo metodológico defende a existência de uma ruptura entre a ideia positivista de separação do ser e do dever ser, construindo novas relações entre o Direito e a Moral $^{10}$. Vários fatores contribuíram para o advento do neopositivismo, dentre eles merecem destaque o declínio da Escola da Exegese, a nova hermenêutica jurídica, a incidência da força normativa da Constituição e a natureza contratual do Estado.

Já sob o enfoque jurídico o Neoconstitucionalismo está assentado na constitucionalização dos direitos infraconstitucionais, na ampliação das garantias processuais, na efetivação dos direitos fundamentais, e na reformulação da atuação do Ministério Público e na expansão da jurisdição constitucional.

Embora não exista uniformidade na doutrina sobre as características do Neoconstitucionalismo, podem ser mencionadas: a adoção de uma noção de Constituição, denominada "modelo prescritivo de Constituição como norma"; a defesa da tese em que o Direito também é composto por princípios; a adoção da técnica interpretativa da "ponderação" ou do "balanceamento" e a integração da jurisprudência às tarefas

\footnotetext{
${ }^{7}$ CAMBI, Eduardo. Neoconstitucionalismo e neoprocessualismo. In: Panóptica, Vitória, ano 1, n. 6, fev. 2007, p. 1-44. Disponível em: 〈http: www.panoptica.org>. Acesso em 20. set. 2017, p. 02.

${ }^{8}$ Ibidem, 2011, p. 29.

${ }^{9}$ CAMBI, Eduardo. Op. Cit., 2016, p. 100.

${ }^{10}$ Ibidem, p. 29.
} 
Revista Eletrônica de Direito Processual - REDP.

Rio de Janeiro. Ano 12. Volume 19. Número 1. Janeiro a Abril de 2018

Periódico Quadrimestral da Pós-Graduação Stricto Sensu em Direito Processual da UERJ

Patrono: José Carlos Barbosa Moreira (in mem.). ISSN 1982-7636. pp. 83-106

www.redp.uerj.br

pragmáticas da Teoria do Direito ${ }^{11}$. Nesse sentido, deve ser ressaltada, entre as principais

características do Neoconstitucionalismo, o advento do conceito de norma jurídica enquanto produto da interpretação de regras e princípios aplicados ao caso concreto.

Uma Constituição que contém base pluralista, como a brasileira de 1988, veicula princípios que, ao serem aplicados, exigem a utilização de métodos de ponderação para que chegue à solução mais justa ao conflito ${ }^{12}$. Em outras palavras, para o Neoconstitucionalismo, os princípios integram a formulação das normas jurídicas, enquanto que para o positivismo jurídico eles não eram reconhecidos como normas, possuindo apenas a função acessória de preencher lacunas, quando estas não eram solucionadas com a aplicação da analogia ou dos costumes ${ }^{13}$.

Isso porque a Constituição passa a ser considerada um sistema aberto de princípios e de regras, sendo estas normas descritivas de comportamento, com caráter deontológico e deôntico, enquanto aqueles são normas finalísticas, de dever ser, com caráter deontológico e teleológico ${ }^{14}$. Outra característica do Neoconstitucionalismo é a constitucionalização do direito. Logo, os institutos jurídicos fundamentais de cada ramo do Direito possuem regulamentação constitucional, seja na forma de regras ou de princípios ${ }^{15}$.

A constitucionalização dos direitos materiais e processuais tem como consequência estender o controle de constitucionalidade, já que uma característica marcante do Neoconstitucionalismo é a onipresença da Constituição. Tal característica pode ser observada no plano de fundo de cada regra legal, posto que há uma norma constitucional que a confirme ou a contradiga por meio de valores, princípios, direitos e garantias fundamentais, além de diretrizes para a esfera pública e privada. As Constituições contemporâneas possuem um conteúdo material denso, abrangendo quase todos os problemas jurídicos, sendo difícil conceber problematizações que não encontrem respostas no texto constitucional ${ }^{16}$.

Com efeito, outra característica fundamental do Neoconstitucionalismo é a extensão da jurisdição constitucional. A Constituição Federal de 1988 ampliou os poderes dos

\footnotetext{
${ }^{11}$ DUARTE, Écio Oto Ramos; POZZOLO, Susana. Neoconstitucionalismo e positivismo jurídico: as faces da teoria do direito em tempos de interpretação moral da constituição. São Paulo: Landy Editora, 2006, p. 79.

${ }^{12}$ FILIPPO, Thiago Baldani Gomes De. Op. Cit., p. 66.

${ }^{13}$ CAMBI, Eduardo. Op. Cit., 2016, p. 106.

${ }^{14}$ Ibidem, 2016, p. 111.

${ }^{15}$ FILIPPO, Thiago Baldani Gomes De. Op. Cit., p. 73.

${ }^{16}$ CAMBI, Eduardo. Op. Cit., p. 74.
} 
Revista Eletrônica de Direito Processual - REDP.

Rio de Janeiro. Ano 12. Volume 19. Número 1. Janeiro a Abril de 2018

Periódico Quadrimestral da Pós-Graduação Stricto Sensu em Direito Processual da UERJ

Patrono: José Carlos Barbosa Moreira (in mem.). ISSN 1982-7636. pp. 83-106

www.redp.uerj.br

juízes, ressaltando a sua atuação como meio de harmonizar a relação com os demais poderes, seja pelo controle de constitucionalidade, seja na análise da legalidade dos atos praticados pela administração pública, bem como na efetivação dos direitos humanosfundamentais ${ }^{17}$. O Judiciário deixou de ser mera "boca da lei", e passou a ser protagonista na concretização das normas jurídicas, inclusive com a possibilidade de controle das políticas públicas indispensáveis à promoção dos direitos fundamentais.

\section{CONSIDERAÇÕES SOBRE O NEOPROCESSUALISMO}

O Neoconstitucionalismo decorre do fenômeno da constitucionalização do direito infraconstitucional. Os ordenamentos processuais contemporâneos tomaram a Constituição como ponto de partida para a interpretação e a argumentação jurídica, retirando da centralidade das leis e dos Códigos, os quais ficaram submetidos aos comandos constitucionais $^{18}$. Tal fenômeno pode ser observado na Constituição Federal de 1988, a qual prevê um amplo rol de garantias processuais fundamentais (v.g., art. $5^{\circ}$, incs. V, XXXV, LIV, LV, LVI e LVII).

Ademais, a expressão "acesso à justiça" não pode ser interpretada apenas em seu sentido estrito, mas contempla interpretação extensiva para que alcance todos os seus significados. Dentre eles, devem ser destacados: i) o ingresso em juízo; ii) a observância das garantias compreendidas na cláusula do devido processo legal; iii) a participação dialética na formação do convencimento do juiz, que irá julgar a causa (efetividade do contraditório); iv) a adequada e tempestiva análise, pelo juiz, natural e imparcial, das questões discutidas no processo (decisão justa e motivada); v) a construção de técnicas processuais adequadas à tutela dos direitos materiais (instrumentalidade do processo e efetividade dos direitos); vi) amplos meios de autocomposição do litígio para, inclusive, inibirem a judicialização de demandas ${ }^{19}$.

\footnotetext{
${ }^{17}$ BRUNO, Susana. Conciliação: prática interdisciplinar e ferramentas para a satisfação do jurisdicionado. Belo Horizonte: Fórum, 2012, p. 28.

${ }^{18}$ CAMBI, Eduardo. Op. Cit., p. 22 e 23.

${ }^{19}$ Ibidem, p. 25.
} 
Revista Eletrônica de Direito Processual - REDP.

Rio de Janeiro. Ano 12. Volume 19. Número 1. Janeiro a Abril de 2018

Periódico Quadrimestral da Pós-Graduação Stricto Sensu em Direito Processual da UERJ

Patrono: José Carlos Barbosa Moreira (in mem.). ISSN 1982-7636. pp. 83-106

www.redp.uerj.br

Nessa linha argumentativa, o artigo $1^{\circ}$ do Novo Código de Processo Civil foi taxativo ao afirmar que o "processo civil será ordenado, disciplinado e interpretado conforme os valores $e$ as normas fundamentais estabelecidos na Constituição da República Federativa do Brasil, observando-se as disposições deste Código”.

A percepção do processo a partir da Constituição como instrumento de realização da justiça contribuiu para a aproximação entre direito material e direito processual. Tal perspectiva representa uma importante inovação, já que até meados do século XIX imperava o sincretismo, no qual direito processual e direito material eram considerados a mesma coisa, uma vez que a relação jurídica processual não possuía autonomia e a ação judicial era considerada como o próprio direito material.

Como reação ao sincretismo, com destaque para a evolução do direito processual civil na Alemanha e na Itália, foi desenvolvida a fase autonomista ou conceitual, a partir da segunda parte do século XIX. Neste período, houve o surgimento de uma ciência processual, com destaque para as teorias processuais contendo os pressupostos processuais e as condições da ação ${ }^{20}$. Ocorre que o processo era considerado apenas como instrumento técnico, o que fomentou o apego excessivo às formas, em prejuízo à promoção da justiça das decisões.

Nessa linha evolutiva, surgiu a fase instrumentalista, pela qual o processo não existe para ser um fim em si mesmo, mas para ser um meio para a tutela jurisdicional. $\mathrm{O}$ direito processual constitucional permitiu a ampliação dos conceitos e das estruturas, bem como a superação dos limites conceituais de cada um dos ramos do direito processual, o que possibilitou o desenvolvimento de uma teoria geral do processo, bem como da maior interação entre Direito, política e sociedade ${ }^{21}$.

No final da década de setenta do século passado, Mauro Cappelletti e Bryan Garth conduziram o Projeto de Acesso à Justiça de Florença, onde propuseram três ondas renovatórias, com destaque para o aperfeiçoamento da assistência judiciária gratuita, para a tutela dos direitos supraindividuais, como as demandas relacionadas ao direito do consumidor e ambiental, bem como para a melhoria no modo de ser do processo, como a simplificação do processo por meio de métodos alternativos de resolução de conflitos,

\footnotetext{
${ }^{20}$ CINTRA, Antonio Carlos de Araújo; GRINOVER, Ada Pellegrini; DINAMARCO, Cândido Rangel. Teoria Geral do Processo. 31 a edição, revista e atualizada. São Paulo: Malheiros, 2015, p. 65.

${ }^{21}$ Ibidem, p. 66.
} 
Revista Eletrônica de Direito Processual - REDP.

Rio de Janeiro. Ano 12. Volume 19. Número 1. Janeiro a Abril de 2018

Periódico Quadrimestral da Pós-Graduação Stricto Sensu em Direito Processual da UERJ

Patrono: José Carlos Barbosa Moreira (in mem.). ISSN 1982-7636. pp. 83-106

www.redp.uerj.br

objetivando maior efetividade do acesso à ordem jurídica justa.

A primeira onda de acesso à justiça estava voltada à disponibilização de meios de acesso ao judiciário à população hipossuficiente, a fim de que os serviços judiciários fossem universalizados. Em decorrência disso, surgiram as defensorias públicas e a assistência judiciária gratuita.

Já a segunda onda teve a preocupação com os direitos e interesses difusos e coletivos, reconhecendo que a tutela jurisdicional não se pauta apenas na proteção de direitos e interesses individuais. Reconheceu-se a necessidade de proteção de áreas como o meio ambiente, o consumidor, o patrimônio público e a probidade administrativa.

A terceira onda renovatória da fase instrumentalista surgiu com uma proposta diferenciada em relação às outras fases. Possuindo um olhar não só voltado para a proteção de direitos e ao acesso à justiça, lançou uma visão crítica de como todos esses objetivos podem ser efetivamente alcançados e realizados por meio da aplicação do Direito. Buscou a concreta realização do direito no plano exterior ao processo, a criação de meios flexíveis de atuação jurisdicional e as reformas das leis processuais para que estas forneçam meios para que a efetiva, adequada e rápida tutela jurisdicional fosse alcançada ${ }^{22}$.

É possível referir-se a aspectos positivos e negativos da instrumentalidade do processo: a) positivamente, ressalta-se a luta pela real efetividade do processo na promoção de uma ordem jurídica justa; b) negativamente, firma-se a noção de que o processo não é um fỉm em si mesmo. As regras processuais devem estar voltadas à realização da justiça, colocando-se o formalismo como uma deturpação do processo.

Assim, a instrumentalidade entre o direito material e o processual pode ser explicada por meio de uma relação de complementariedade estabelecida entre um arquiteto e um engenheiro, como argumenta Fredie Didier $\mathrm{Jr}^{23}$, pois cabe ao direito material projetar, enquanto compete ao direito processual a concretização desse projeto. Logo, o processo deve ser pautado pelo direito material, que possui influência direta sobre a criação, a interpretação e a aplicação das regras processuais.

Ou, como advertia José Carlos Barbosa Moreira ${ }^{24}$, ao afirmar que técnica e

\footnotetext{
${ }^{22}$ BUENO, Cassio Scarpinella. Curso sistematizado de direito processual civil. Vol.1. $8^{\mathrm{a}}$ ed. rev. e atual. São Paulo: Saraiva, 2014, p. 84 e 85.

${ }^{23}$ DIDIER JÚNIOR, Fredie. Curso de direito processual civil: introdução ao direito processual civil, parte geral e processo de conhecimento. 17 a ed. Salvador: Ed. Jus Podivm, 2015, p. 39.

${ }^{24}$ MOREIRA, José Carlos Barbosa. Efetividade do processo e técnica processual. Revista de processo, vol.
} 
Revista Eletrônica de Direito Processual - REDP.

Rio de Janeiro. Ano 12. Volume 19. Número 1. Janeiro a Abril de 2018

Periódico Quadrimestral da Pós-Graduação Stricto Sensu em Direito Processual da UERJ

Patrono: José Carlos Barbosa Moreira (in mem.). ISSN 1982-7636. pp. 83-106

www.redp.uerj.br

efetividade processual não são valores contrastantes ou incompatíveis: "quando porventura nos pareça que a solução técnica de um problema elimina ou reduz a efetividade do

processo, desconfiemos, primeiramente, de nós mesmos. É bem provável que estejamos confundindo os limites da técnica com os da nossa própria incapacidade de dominá-la e de explorar a fundo as virtualidades. A preocupação com a efetividade deveria levar-nos amiúde a lamentar menos as exigências, reais ou supostas, imputadas à técnica do que a escassa habilidade com que nos servimos dos recursos por ela mesma colocadas à nossa disposição".

A fase instrumentalista está em andamento, sendo muito importante para a efetivação das ondas renovatórias pensadas pelo Projeto de Acesso à Justiça, iniciado em Florença, e dos desafios contemporâneos do Direito Processual Civil. Nesse contexto evolutivo, é importante que a visão instrumentalista seja potencializada pela premissa metodológica do Neoconstitucionalismo. Dessa forma, o Neoprocessualismo aparece como uma nova fase do direito processual, em que a compreensão do processo se dá pela perspectiva do Neoconstitucionalismo ${ }^{25}$.

Novas formas de resoluções de conflitos ganham espaço para reduzir o fenômeno da judicialização das demandas, dar maior racionalidade e efetividade ao sistema processual, bem como proporcionar a melhor pacificação social dos conflitos. Assim, práticas como a conciliação, mediação, arbitragem, justiça restaurativa e constelações sistêmicas surgem como alternativas mais acessíveis e eficazes para a resolução de diversos tipos de conflitos, tanto na esfera cível quanto na penal.

\section{NEOPROCESSUALISMO E MÉTODOS ALTERNATIVOS DE RESOLUÇÃO DE CONFLITOS: NEOINSTRUMENTALISMO?}

O excesso de judicialização de demandas e o abuso do direito processual, por parte dos litigantes habituais, associado a ausência de universalidade no acesso à justiça e a

77, jan.-mar./1995, p. 877-888.

${ }^{25}$ DONIZETTI, Elpídio. Evolução (fases) do processualismo: sincretismo, autonomia, instrumentalismo e neoprocessualismo. $2012 . \quad$ Disponível em: https://elpidiodonizetti.jusbrasil.com.br/artigos/121940209/evolucao-fases-do-processualismo-sincretismoautonomia-instrumentalismo-e-neoprocessualismo>. Acesso em 10 out. 2017. 
Revista Eletrônica de Direito Processual - REDP.

Rio de Janeiro. Ano 12. Volume 19. Número 1. Janeiro a Abril de 2018

Periódico Quadrimestral da Pós-Graduação Stricto Sensu em Direito Processual da UERJ

Patrono: José Carlos Barbosa Moreira (in mem.). ISSN 1982-7636. pp. 83-106

www.redp.uerj.br

lentidão na prestação jurisdicional, são fatores de degradação da legitimação do Poder Judiciário perante a sociedade brasileira contemporânea ${ }^{26}$.

O Neoprocessualismo, conforme asseverado, é um método pelo qual o processo deve ser concebido, interpretado e aplicado a partir dos valores, diretrizes, princípios e garantias constitucionais. Com isso, o acesso à justiça, a dignidade da pessoa humana, o devido processo legal e sua duração razoável passam a ter grande influência para o desenvolvimento de formas alternativas de resolução de conflitos.

É necessário romper com o formalismo processual, apostando na desformalização para a mais rápida solução aos litígios, bem como na delegalização, marcada pela concessão de maior liberdade para as soluções não-jurisdicionais (juízos de equidade) ${ }^{27}$.

A partir do momento em que os diversos ramos do Direito passaram a ser estudados, analisados e sistematizados pela Constituição Federal de 1988, o Direito Processual ganhou uma visão diferenciada. Por meio de novos enfoques, houve o abandono da visão processual unitária, predominantemente técnica, fato este que propiciou a maior conscientização de que valores e fins exteriores e estranhos às formalidades dos processos devem ser alcançados e realizados ${ }^{28}$.

Embora a preocupação com a forma também seja expressão de garantias, como o contraditório, a ampla defesa, a legalidade e a impessoalidade, o seu pleno exercício pressupõe grande demora para a resolução das demandas, muitas vezes resumidas em decisões finais que não proporcionam utilidade, muito menos satisfação para os sujeitos processuais $^{29}$. Ainda que a observância de todas as garantias fundamentais expresse a dimensão democrática do Estado de Direito, as soluções consensuais são, em muitos casos, mais adequadas do que uma decisão judicial imposta.

Dessa forma, é de fundamental importância que a aplicação de métodos alternativos à resolução judicial dos conflitos seja destacada para a melhor e mais rápida tutela dos direitos $^{30}$. O Novo Código de Processo Civil (Lei $\left.n^{\mathbf{o}} 13.105 / 15\right)$ promoveu a maior

\footnotetext{
${ }^{26}$ DINAMARCO, Cândido Rangel. A instrumentalidade do processo. 15ª ed. São Paulo: Malheiros, 2013, p. 168.

${ }^{27}$ CINTRA, Antonio Carlos de Araújo; GRINOVER, Ada Pellegrini; DINAMARCO, Cândido Rangel. Op. Cit., p. 49.

${ }^{28}$ BUENO, Cassio Scarpinella. Op. Cit., p. 84.

${ }^{29}$ AMENDOEIRA JR, Sidnei. Manual de direito processual civil. Vol. 1. $2^{\mathrm{a}}$ ed. São Paulo: Saraiva, 2012, p. 34.

${ }^{30}$ CÂMARA, Alexandre Freitas. O novo processo civil brasileiro. São Paulo: Atlas, 2015, p. 32.
} 
Revista Eletrônica de Direito Processual - REDP.

Rio de Janeiro. Ano 12. Volume 19. Número 1. Janeiro a Abril de 2018

Periódico Quadrimestral da Pós-Graduação Stricto Sensu em Direito Processual da UERJ

Patrono: José Carlos Barbosa Moreira (in mem.). ISSN 1982-7636. pp. 83-106

www.redp.uerj.br

aproximação entre o processo civil e a Constituição, o que permite vislumbrar a existência de um sistema multiportas de acesso à ordem jurídica justa, priorizando a cooperação, a boa-fé, a prevalência do campo material sobre o formal, o diálogo processual, a não surpresa, a duração razoável do processo; enfim, a utilização do processo como instrumento para a concretização dos valores, princípios e regras constitucionais ${ }^{31}$.

Nessa interação entre Direito Civil, Direito Constitucional e Direito Processual Civil, tais disciplinas não perderam suas essências. Consequentemente, o Direito Civil Constitucional $^{32}$, por exemplo, deve ser visto como um novo caminho metodológico a partir da eficácia horizontal dos direitos fundamentais, a qual procura analisar e proporcionar soluções aos conflitos privados a partir dos pressupostos constitucionais, bem como buscar interpretar o Código Civil e a legislação infraconstitucional à luz da Constituição, conforme também prevê o art. $1^{\circ}$ do novo Código de Processo Civil ${ }^{33}$.

O descontentamento com a resposta jurisdicional tradicional, resultante da crítica ao processo como um fim em si mesmo, potencializaram o Neoprocessualismo na busca de respostas mais adequadas para promover a maior eficiência do sistema processual. A fase metodológica da instrumentalidade do processo possui o escopo de tornar o tradicional processo mais acessível e efetivo; porém, com o novo Código de Processo Civil os métodos de solução consensual de conflitos foram estimulados, seja para evitar a judicialização de demandas, seja para que a autocomposição se realize no curso do processo judicial.

Logo, a jurisdição deixa de ser a categoria central da teoria geral do processo, porque se reconhece que o Estado não é o único detentor do poder e que os litigantes não são meros objetos do processo ${ }^{34}$, mas são cidadãos/protagonistas da solução dos conflitos para que a pacificação social aconteça, de preferência, extrajudicialmente. Nessa perspectiva, poderia se afirmar que está em curso não apenas a evolução da terceira onda de acesso à justiça, mas sim o advento de uma nova fase, o "Neoinstrumentalismo", o qual

\footnotetext{
${ }^{31}$ VASCONCELOS, Carlos Eduardo de. Mediação de conflitos e práticas restaurativas. $4^{\mathrm{a}}$ ed. rev., atual. e ampl. Rio de Janeiro: Forense; São Paulo: Método, 2015, p. 86.

32 CAMBI, Eduardo; FOGAÇA, Marcos Vargas. Direito Civil Constitucional. Revista de direito privado, vol. 61, jan.-mar. 2015, p. 13-35.

33 TARTUCE, Flávio. Impactos do novo CPC no Direito Civil. Rio de Janeiro: Forense; São Paulo: Método, 2015 , p. 26 e 28.

${ }^{34}$ ABBOUD, Georges; OLIVEIRA, Rafael Tomaz de. O dito e o não-dito sobre a instrumentalidade do processo: críticas a partir de uma exploração hermenêutica da teoria processual. Revista de processo, vol. 166, dez./2008, p. 27-70.
} 
Revista Eletrônica de Direito Processual - REDP.

Rio de Janeiro. Ano 12. Volume 19. Número 1. Janeiro a Abril de 2018

Periódico Quadrimestral da Pós-Graduação Stricto Sensu em Direito Processual da UERJ

Patrono: José Carlos Barbosa Moreira (in mem.). ISSN 1982-7636. pp. 83-106

www.redp.uerj.br

pode ser observado na busca por maior eficiência na produção de resultados práticos e satisfatórios para todas as partes envolvidas no conflito por meio dos diversos métodos, inclusive atípicos, de composição de litígios.

O Neoinstrumentalismo ou pós-instrumentalismo, portanto, se propõe a fazer uma releitura do escopo jurídico da terceira onda de acesso à justiça, a partir da ótica da efetivação dos Direitos Fundamentais ${ }^{35}$, com a finalidade de promover a cidadania e levar a sério as promessas constitucionais.

O fenômeno do Neoinstrumentalismo está sendo impulsionado por diversos fatores, como: as dificuldades econômicas e formais que bloqueiam o ingresso das pessoas em juízo; o modo de ser do processo, o qual busca em primazia a ordem legal dos fatos e suas formalidades, esquecendo a realidade social apresentada em cada caso; a forma como se busca a justiça das decisões, bem como a falta de efetividade da prestação jurisdicional ${ }^{36}$.

Aliás, como já asseverado, o Novo Código de Processo Civil priorizou e valorizou a busca por soluções consensuais aos conflitos, viabilizando os pressupostos do Neoinstrumentalismo, destacados, dentre outros, no artigo $3^{\mathrm{o} 37}$. Nos termos dos parágrafos $2^{\circ}$ e $3^{\circ}$ deste artigo, afirma-se que o Estado promoverá a solução consensual de conflitos, sempre que possível, bem como incentivará a aplicação da conciliação, da mediação e de outros métodos de solução consensual de conflitos, os quais deverão ser estimulados por juízes, advogados, defensores públicos e membros do Ministério Público, inclusive no curso do processo judicial.

Considerando que o Poder Público é um dos litigantes habituais, responsáveis pela sobrecarga de processos e pela lentidão na prestação jurisdicional ${ }^{38}$, é indispensável que os métodos de solução consensual de conflitos sejam adotados pelo Estado. Tanto isso é importante que o Enunciado $n^{\circ} 573$ do Fórum Permanente de Processualistas Civis afirma que as "Fazendas Públicas devem dar publicidade às hipóteses em que seus órgãos de Advocacia Pública estão autorizados a aceitar a autocomposição”.

\footnotetext{
35 JOBIM, Marco Félix. As Fases Metodológicas do Processo. Disponível em: <http://www.reajdd.com.br/artigos/ed8-7.pdf>. Acesso em 10. dez. 2017, p. 15.

${ }^{36}$ COSTA, Rafael Lançoni da. Reflexões sobre o Direito Processual Coletivo. In: Revista do Mestrado em Direito da Universidade Católica de Brasília RVMD. V. 6, nº 2, p. 269-296, Jul-Dez, 2012, p. 274.

${ }^{37}$ NEVES, Daniel Amorim Assumpção. Manual de direito processual civil. Volume único. 8. ed. Salvador: Ed. JusPodivm, 2016, p. 84.

${ }^{38}$ CAMBI, Eduardo; PEREIRA, Fabricio Fracaroli. Estratégia nacional de prevenção e redução de litígios. Revista de processo, vol. 237, nov. 2014, p. $435-457$.
} 
Revista Eletrônica de Direito Processual - REDP.

Rio de Janeiro. Ano 12. Volume 19. Número 1. Janeiro a Abril de 2018

Periódico Quadrimestral da Pós-Graduação Stricto Sensu em Direito Processual da UERJ

Patrono: José Carlos Barbosa Moreira (in mem.). ISSN 1982-7636. pp. 83-106

www.redp.uerj.br

Outra modificação importante trazida pelo Novo Código de Processo Civil, no art.

334, foi a audiência de conciliação ou mediação. Ao ser citado (art. 250, inc. IV, NCPC), o reú deve ser advertido de que, caso não compareça a tal audiência, restará configurado ato atentatório à dignidade da justiça, que pode ser repreendido com a imposição da multa prevista no art. 334, $\S 8^{\circ}$, do NCPC (cfr. Enunciado no 273 do Fórum Permanente de Processualistas Civis).

Em razão do destaque dado aos meios de autocomposição no Novo Código de Processo Civil, é possível afirmar que os métodos consensuais de soluções de controvérsias deixaram de ocupar posição subalterna, rompendo definitivamente os resquícios do formalismo presente no CPC de 1973, para assumirem a condição de novos instrumentos da promoção da paz social ${ }^{39}$.

Tal escopo foi observado desde a exposição de motivos do anteprojeto do Novo Código de Processo Civil, onde foi salientada a preocupação de converter o processo em um instrumento que incluísse também o contexto social em que produziria os seus efeitos. Houve a preocupação em proporcionar às próprias partes a oportunidade de porem fim aos conflitos, alcançando uma satisfação muito mais efetiva em decorrência de não ter sido imposta pelo Estado-juiz ${ }^{40}$.

A autocomposição está assentada na participação ativa dos próprios litigantes na solução do conflito de interesses ${ }^{41}$, substituindo a necessidade do Poder Judiciário ditar coercitivamente a decisão para o caso concreto. A autocomposição é o gênero do qual são espécies a transação, a submissão, e a renúncia. Na transação, há um sacrifício mútuo de interesses visando a resolução do conflito, já na submissão e na renúncia há o exercício unilateral da vontade, podendo ser consideradas soluções altruístas, já que o término do conflito dá-se pela renúncia do direito ou pela submissão à pretensão contrária. Quando verificados durante um processo judicial, o juiz homologará por sentença de mérito a autocomposição, nos termos do art. 487, inciso III, no Novo CPC ${ }^{42}$.

Com efeito, o neoprocessualismo busca, ao máximo, a solução efetiva e eficiente de

\footnotetext{
${ }^{39}$ VASCONCELOS, Carlos Eduardo de. Mediação de conflitos e práticas restaurativas. $4^{\mathrm{a}}$ ed. rev., atual. e ampl. Rio de Janeiro: Forense; São Paulo: Método, 2015, p. 87.

${ }^{40}$ GAJARDONI, Fernando da Fonseca. Teoria geral do processo: comentários ao CPC de 2015: parte geral. São Paulo: Forense, 2015, p. 50.

${ }^{41}$ BRUNO, Susana. Op. Cit., p. 59.

${ }^{42}$ NEVES, Daniel Amorim Assumpção. Op. Cit., p. 87.
} 
Revista Eletrônica de Direito Processual - REDP.

Rio de Janeiro. Ano 12. Volume 19. Número 1. Janeiro a Abril de 2018

Periódico Quadrimestral da Pós-Graduação Stricto Sensu em Direito Processual da UERJ

Patrono: José Carlos Barbosa Moreira (in mem.). ISSN 1982-7636. pp. 83-106

www.redp.uerj.br

conflitos, apontando que esses objetivos podem ser alcançados com as diversas formas de resolução consensual dos litígios, como a negociação, a mediação, a conciliação, a arbitragem e outros métodos menos utilizados como a avaliação neutra, a facilitação de diálogos apreciativos e os comitês de resolução de disputas ${ }^{43}$, além das práticas da Justiça Restaurativa e das Constelações Sistêmicas. Ressalta-se que a aplicação de tais métodos não significa a renúncia ao ingresso no Poder Judiciário, nem a decretação da falência do sistema judicial, mas representa uma nova perspectiva ao acesso à justiça e à tutela dos direitos.

Observa-se que o Novo Código Processual Civil regulamentou e diferenciou as atividades de conciliação e mediação, além de permitir a aplicação de outros métodos de solução consensual de conflitos, não trazendo apenas disposições principiológicas, mas diretrizes estruturais e procedimentais ${ }^{44}$.

A mediação possui grande semelhança com a conciliação, pois as partes interessadas utilizam uma terceira pessoa como intermediador para que se alcance a resolução do conflito. A grande diferença entre os institutos está no método: enquanto na mediação se busca trabalhar o conflito, tendo o acordo como consequência, na conciliação se pretende o efetivo acordo entre as partes.

Outra diferença é prevista expressamente pelo art. $165, \S \S 2^{\circ}$ e $3^{\circ}$ do Novo Código de Processo Civil, que delimita a atuação do conciliador e do mediador. Nos termos do parágrafo $2^{\circ}$ do citado artigo, o conciliador atuará nos casos em que não existam vínculos anteriores entre as partes, podendo fazer sugestões de possíveis soluções para que o conflito seja cessado. Já, nos moldes do parágrafo $3^{\circ}$ do mesmo dispositivo, deverá ser utilizada a mediação preferencialmente nos casos em que existam vínculos anteriores entre as partes, sendo que o papel do mediador será o de auxiliar os envolvidos a compreenderem as questões da demanda, não manifestando nenhuma sugestão de solução.

Por isso, a mediação pode ser considerada como o meio pelo qual pessoas com entendimentos aparentemente antagônicos podem, com o auxílio de um terceiro imparcial, buscarem a composição amistosa do conflito $^{45}$. O Novo Código de Processo Civil, tal como a Lei 13.140/2015, dispõem sobre a aplicação da mediação para a resolução de

\footnotetext{
${ }^{43}$ VASCONCELOS, Carlos Eduardo de. Op. Cit., p. 55.

${ }^{44}$ NEVES, Daniel Amorim Assumpção. Op. Cit., p. 84.

${ }^{45}$ BRUNO, Susana. Op. Cit., p. 70.
} 
Revista Eletrônica de Direito Processual - REDP.

Rio de Janeiro. Ano 12. Volume 19. Número 1. Janeiro a Abril de 2018

Periódico Quadrimestral da Pós-Graduação Stricto Sensu em Direito Processual da UERJ

Patrono: José Carlos Barbosa Moreira (in mem.). ISSN 1982-7636. pp. 83-106

www.redp.uerj.br

conflitos judicializados ou não, que vão desde à esfera particular até ao âmbito da Administração Pública ${ }^{46}$.

A conciliação, também, é um método utilizado por indivíduos com posições aparentemente conflitantes, os quais chegam a um acordo por meio de aconselhamentos e sugestões apresentadas por um terceiro. Diferencia-se, portanto, da negociação, na qual as partes chegam a uma transação sem a intervenção da figura do terceiro conciliador ${ }^{47}$. Na conciliação, o terceiro não precisa ser imparcial, mas sim ético, para propor soluções, em caráter sugestivo, e não impositivo ${ }^{48}$.

Dentre as novidades trazidas pelo Novo Código de Processo Civil, está a regra prevista no art. 165, caput, para que os tribunais criem centros judiciais de resolução consensual de conflitos. Tais centros serão responsáveis pelo desenvolvimento de programas de autocomposição, bem como pela realização dos procedimentos de mediação e conciliação ${ }^{49}$. Ressalta-se que tal dispositivo veio consagrar a Política Judiciária Nacional de tratamento adequado dos conflitos de interesses no âmbito do Poder Judiciário, regulamentada pela Resolução $\mathrm{n}^{\circ}$ 125/2010 do Conselho Nacional de Justiça.

A arbitragem, por sua vez, é prevista no ordenamento jurídico brasileiro na Lei $\mathrm{n}^{\circ}$ 9.307/1996, e, diferentemente do procedimento adotado pela mediação e conciliação, o papel do terceiro imparcial é colher as provas, ponderar os argumentos de ambas as partes e decidir o conflito com a apresentação de um laudo ou sentença arbitral irrecorrível ${ }^{50}$. Logo, o principal objetivo do terceiro não é facilitar o entendimento entre as partes, mas sim proferir a decisão do problema, após o processo de produção de provas e argumentação das partes.

Tal forma de solução de conflitos só pode ser aplicada em demandas que envolvam direitos disponíveis, ainda que envolvam a Administração Pública direta e indireta (art. $1^{\circ}$, $\S 1^{\circ}$, da Lei $n^{\circ}$ 9.307/1996). Por se respeitar o caráter voluntário da submissão de eventuais litígios aos procedimentos alternativos de solução de controvérsias, a arbitragem não afronta o princípio da inafastabilidade da jurisdição, encontrado no art. $5^{\circ}$, inciso XXXV, da Constituição da República Federativa do Brasil, de 1988, conforme orientação do

\footnotetext{
${ }^{46}$ VASCONCELOS, Carlos Eduardo de. Op. Cit., p. 115.

${ }^{47}$ NEVES, Daniel Amorim Assumpção. Op. Cit., p. 88.

${ }^{48}$ BRUNO, Susana. Op. Cit., p. 71.

${ }^{49}$ NEVES, Daniel Amorim Assumpção. Op. Cit., p. 91.

${ }^{50}$ VASCONCELOS, Carlos Eduardo de. Op. Cit., p. 61.
} 
Revista Eletrônica de Direito Processual - REDP.

Rio de Janeiro. Ano 12. Volume 19. Número 1. Janeiro a Abril de 2018

Periódico Quadrimestral da Pós-Graduação Stricto Sensu em Direito Processual da UERJ

Patrono: José Carlos Barbosa Moreira (in mem.). ISSN 1982-7636. pp. 83-106

www.redp.uerj.br

Supremo Tribunal Federal (SE 5206 AgR, Relator(a): Min. SEPÚLVEDA PERTENCE,

Tribunal Pleno, julgado em 12/12/2001, DJ 30-04-2004 PP-00029 EMENT VOL-0214906 PP-00958).

Tal posicionamento foi observado no caput do art. $3^{\circ}$ do Novo Código de Processo Civil, em conjunto com o parágrafo $1^{\circ}$, os quais dispõem que não se excluirá da apreciação jurisdicional ameaça ou lesão a direito, sendo, contudo, permitido o uso da arbitragem, na forma da lei.

Sobre a Justiça Restaurativa, ainda não há um consenso doutrinário sobre o seu conceito. Howard Zehr ${ }^{51}$ sustenta que não pode ocorrer uma conceituação rígida, explicando que a Justiça Restaurativa é uma abordagem que visa promover justiça ao envolver, tanto quanto possível, todos aqueles que têm interesse na reparação de uma ofensa ou de um dano específico, bem como em um processo que coletivamente verifica e trata os danos, necessidades e responsabilidades decorrentes da ofensa, com o objetivo de restabelecer os vínculos entre as pessoas envolvidas e, destarte, promover a cultura da paz.

No Brasil, a Justiça Restaurativa é aplicável, porém, de maneira mitigada, principalmente no âmbito do Direito Penal, pois ainda predomina uma visão restrita do princípio da indisponibilidade da ação penal pública ${ }^{52}$. Porém, após a promulgação da Lei dos Juizados Especiais (Lei n ${ }^{\circ}$ 9.099/95) e do advento da Constituição da República Federativa do Brasil de 1988, tal princípio foi mitigado, posto que o artigo 98, inciso I, da CF possibilitou ao Ministério Público a realização de transação penal com o autor do fato, desde que a infração penal seja de menor potencial ofensivo. Tal regra foi regulamentada pela Lei $\mathrm{n}^{\text {o }} 9.099 / 95$, a qual substituiu o princípio da obrigatoriedade pelo chamado "princípio da discricionariedade regrada".

Com efeito, o Ministério Público pode dispor da ação penal pública e realizar a transação, nos casos permitidos pela lei. Em 2005, o Instituto de Direito Comparado e Internacional de Brasília apresentou ao Congresso Nacional, a Sugestão n 099/2005, para proporcionar a utilização de procedimentos de Justiça Restaurativa no sistema de justiça criminal brasileiro ${ }^{53}$. Tal sugestão transformou-se no Projeto de Lei $n^{\circ} 7.006 / 06$, que

\footnotetext{
${ }^{51}$ ZEHR, Howard. Justiça Restaurativa. Tradução Tônia Van Acker. São Paulo: Palas Athena, 2015, p. 54.

${ }^{52}$ TIVERON, Raquel. Justiça Restaurativa: a construção de um novo paradigma de justiça criminal. Brasília, DF: Thesaurus, 2014, p. 388.

${ }^{53}$ BIANCHINI, Edgar Hrycylo. Justiça Restaurativa: um desafio à práxis jurídica. Campinas, SP: Servanda Editora, 2012, p. 94.
} 
Revista Eletrônica de Direito Processual - REDP.

Rio de Janeiro. Ano 12. Volume 19. Número 1. Janeiro a Abril de 2018

Periódico Quadrimestral da Pós-Graduação Stricto Sensu em Direito Processual da UERJ

Patrono: José Carlos Barbosa Moreira (in mem.). ISSN 1982-7636. pp. 83-106

www.redp.uerj.br

propunha alterações no Código Penal Brasileiro, no Código de Processo Penal e na Lei dos

Juizados Especiais Cíveis e Criminais. Contudo, o Projeto de Lei foi arquivado, mesmo tendo um grande potencial para a regulamentação da aplicação desta importante forma de resolução de conflitos.

No entanto, em 31 de maio de 2016, a Justiça Restaurativa ganhou um grande impulso no Brasil com a aprovação da Resolução n 225/2016 do Conselho Nacional de Justiça. Tal Resolução traz um compilado das normatizações já existentes em alguns Tribunais que adotam as práticas restaurativas, incentivando a sua aplicação por todos os Tribunais de Justiça. Vale destacar que diversos projetos piloto trabalham com a Justiça Restaurativa no Brasil, com ênfase na aplicação a jovens infratores, conflitos intrafamiliares e no âmbito escolar.

A Justiça Restaurativa também é uma realidade em diversas unidades do Ministério Público brasileiro, em especial a partir da Resolução $n^{\circ}$ 118/2014, do Conselho Nacional do Ministério Público, cujos artigos 13 e 14, recomenda as práticas restaurativas nas situações para as quais seja viável a busca da reparação dos efeitos da infração por intermédio da harmonização entre o (s) seu (s) autor (es) e a (s) vítima (s), com o objetivo de restaurar o convívio social e a efetiva pacificação dos relacionamentos, mediante a formulação, pelas partes envolvidas e com a ajuda de um facilitador, de um plano restaurativo para a reparação ou minoração do dano, a reintegração do infrator e a harmonização social.

O Ministério Público do Paraná ${ }^{54}$, por exemplo, lançou no ano de 2015 o projeto "MP Restaurativo e a Cultura da Paz”, com o propósito de divulgar e estimular os meios autocompositivos de conflitos, visando a prevenção de violências, a diminuição dos índices de reincidência, a responsabilização dos ofensores, o diálogo entre as partes e a conscientização sobre todos os aspectos do conflito. Já, em 07 de agosto de 2017, o Conselho Nacional do Ministério Público, ao regulamentar a instauração e a tramitação do procedimento investigatório criminal, na Resolução $\mathrm{n}^{\circ} 181$, mitigou o princípio da indisponibilidade da ação penal pública e ampliou as margens para a construção de soluções negociadas, ao disciplinar, no artigo 18, o acordo da não persecução penal.

\footnotetext{
${ }^{54}$ MINISTÉRIO PÚBLICO DO PARANÁ. MP-PR lança projeto “MP Restaurativo e a Cultura da Paz”. 07. abr. 2015. Disponível em: http://www.mppr.mp.br/modules/noticias/article.php?storyid=5238>. Acesso em 15. out. 2017 , s/p.
} 
Revista Eletrônica de Direito Processual - REDP.

Rio de Janeiro. Ano 12. Volume 19. Número 1. Janeiro a Abril de 2018

Periódico Quadrimestral da Pós-Graduação Stricto Sensu em Direito Processual da UERJ

Patrono: José Carlos Barbosa Moreira (in mem.). ISSN 1982-7636. pp. 83-106

www.redp.uerj.br

Além disso, o método das "Constelações Sistêmicas", conhecido como

“Constelações Familiares”, também é um meio alternativo de resolução de conflitos que vem sendo aplicado no Brasil desde o ano de 2012. Nos conflitos de família, a aplicação de solução consensual, tanto jurisdicional quanto parajurisdicional, é muito adequada, pois os vínculos intersubjetivos que existem entre as partes envolvidas permanecerão existindo após a conclusão da demanda ${ }^{55}$.

O pioneiro na aplicação do método no Brasil foi o Juiz Sami Storch, da $2^{\mathrm{a}}$ Vara de Família de Itabuna, Bahia ${ }^{56}$, o qual faz as seguintes considerações sobre a aplicação do método:

As técnicas aplicadas vêm auxiliando na efetivação de conciliações verdadeiras entre as partes. Durante e após o trabalho com constelações, os participantes têm demonstrado boa absorção dos assuntos tratados, um maior respeito e consideração em relação à outra parte envolvida, além da vontade de conciliar - o que se comprova também com os resultados das audiências de conciliação realizadas semanas depois (os índices de acordos superam os $90 \%$ ) e com os relatos das partes e dos advogados. ${ }^{57}$

Trata-se de procedimento de terapia familiar, criada em 1970, pelo psicanalista alemão Bert Hellinger. Por ser uma terapia, as constelações familiares alcançam resultados maiores do que as conciliações realizadas no Judiciário, uma vez que a terapia da Constelação Sistêmica é pautada no estudo e análise das dinâmicas ocultas nos conflitos, ou seja, tudo aquilo que leva à ocorrência dos mesmos. Tais dinâmicas consistem, portanto, analisar todos os fatores atuais e passados que motivaram a prática da violência ou alguma resistência para a resolução de conflitos de natureza menos graves. Conforme tal teoria, essas dinâmicas ocultas são regidas por leis sistêmicas, as quais Hellinger chamou de Ordens do Amor ${ }^{58}$.

As partes selecionam, entre uma gama de voluntários, representantes para si

\footnotetext{
${ }^{55}$ CÂMARA, Alexandre Freitas. O novo processo civil brasileiro. São Paulo: Atlas, 2015, p. 24.

${ }^{56}$ CONSELHO NACIONAL DE JUSTIÇA. Justiça restaurativa e constelações familiares avançam no Paraná. 04 maio 2017. Disponível em: < http://cnj.jus.br/noticias/judiciario/84704-justica-restaurativa-econstelacoes-familiares-avancam-no-parana>. Acesso em 24. Jun. 2017, s/p.

${ }^{57}$ STORCH, Sami. Direito Sistêmico: primeiras experiências com constelações no judiciário. In: Filosofia, Pensamento e Prática das Constelações Sistêmicas - $n^{\circ}$ 4. São Paulo: Conexão Sistêmica, 2015, s/p.

58 Idem, Por que aprender Direito Sistêmico? 10 abril 2017. Disponível em: < https://direitosistemico.wordpress.com/2017/04/10/por-que-aprender-direito-sistemico/>. Acesso em 25 . set. 2017, s/p.
} 
Revista Eletrônica de Direito Processual - REDP.

Rio de Janeiro. Ano 12. Volume 19. Número 1. Janeiro a Abril de 2018

Periódico Quadrimestral da Pós-Graduação Stricto Sensu em Direito Processual da UERJ

Patrono: José Carlos Barbosa Moreira (in mem.). ISSN 1982-7636. pp. 83-106

www.redp.uerj.br

próprios e para outros membros da família. A partir da escolha, tais representantes irão sentir como se fossem as próprias pessoas que representam e reproduzirão os fatos do conflito. Como em uma peça de teatro, as partes observarão a cena, para poderem compreender fatos e sentimentos que antes lhes eram vedados, podendo, desta forma, chegarem a uma resolução do conflito por meio da compreensão de fatores emocionais e a partir da conscientização de atos indevidos anteriormente ${ }^{59}$.

Dessa forma, observa-se que, com a crescente busca pela paz social e pela efetiva resolução dos conflitos, surgem formas variadas e alternativas para a resolução das mais diversas controvérsias. Tais métodos - ainda que atípicos, desde que estejam de acordo com a Constituição - buscam estimular o diálogo, ampliar a participação da sociedade e a construção de soluções pacíficas e duradouras, em que todos os envolvidos sejam beneficiados.

\section{CONCLUSÃO}

O Neoconstitucionalismo proporcionou a construção de um método adequado para promover os valores, princípios, regras e garantias constitucionais, o que permitiu a revisitação dos postulados do positivismo jurídico. A valorização da Constituição, a normatização dos princípios jurídicos e a aplicação da técnica da ponderação proporcionaram uma nova forma de interpretação e de aplicação do Direito contemporâneo.

Nesse contexto, o Direito Processual também ganhou nova força renovatória. O formalismo processual mostrou-se um obstáculo para a realização da justiça, precisando ser revisto para que o processo fosse concebido como um importante instrumento para a realização do direito material.

A instrumentalidade do processo foi potencializada pelo Neoconstitucionalismo, o que contribui para a evolução do Direito Processual, na medida em que, nos termos do artigo $1^{\mathrm{o}}$ do Novo Código de Processo Civil, o processo deve ser ordenado, disciplinado e interpretado conforme os valores e as normas fundamentais estabelecidos na Constituição da República Federativa do Brasil.

\footnotetext{
${ }^{59}$ HELLINGER, Bert. Ordens do Amor: um guia para o trabalho com constelações familiares. Tradução: Newton de Araújo Queiroz. São Paulo: Editora Cultrix, 2014, p. 11.
} 
Revista Eletrônica de Direito Processual - REDP.

Rio de Janeiro. Ano 12. Volume 19. Número 1. Janeiro a Abril de 2018

Periódico Quadrimestral da Pós-Graduação Stricto Sensu em Direito Processual da UERJ

Patrono: José Carlos Barbosa Moreira (in mem.). ISSN 1982-7636. pp. 83-106

www.redp.uerj.br

Portanto, o Neoconstitucionalismo e o Neoprocessualismo contribuíram para ampliar o acesso à ordem jurídica justa, por meio da aposta em uma nova forma de aplicação do instrumentalismo - o Neoinstrumentalismo - a partir da construção e aplicação de meios típicos e atípicos de resolução consensual de controvérsias, jurisdicionais ou parajurisdicionais, capazes de estimularem a harmonização dos conflitos de interesses, mesmo sem a participação direta do Estado-juiz, dando protagonismo aos litigantes enquanto cidadãos corresponsáveis na resolução das controvérsias e na promoção da cultura da paz.

\section{REFERÊNCIAS BIBLIOGRÁFICAS:}

ABBOUD, Georges; OLIVEIRA, Rafael Tomaz de. O dito e o não-dito sobre a instrumentalidade do processo: críticas a partir de uma exploração hermenêutica da teoria processual. Revista de processo, vol. 166, dez./2008.

AMENDOEIRA JR, Sidnei. Manual de direito processual civil. Vol. 1. $2^{\mathrm{a}}$ ed. São Paulo: Saraiva, 2012.

BARROSO, Luís Roberto. Neoconstitucionalismo e Constitucionalização do Direito: O triunfo tardio do direito constitucional no Brasil. 26. abr. 2006. Disponível em: < https://www.conjur.com.br/2006-abr-26/triunfo_tardio_direito_constitucional_brasil> . Acesso em 12. out. 2017.

BIANCHINI, Edgar Hrycylo. Justiça Restaurativa: um desafio à práxis jurídica. Campinas, SP: Servanda Editora, 2012.

BRASIL. Constituição da República Federativa do Brasil de 1988. Disponível em: <http://www.planalto.gov.br/ccivil_03/Constituicao/Constituicao.htm>. Acesso em 07 out. 2017.

Lei $n^{o}$ 13.105, de 16 de Março de 2015. Código de Processo Civil. Disponível em:< http://www.planalto.gov.br/ccivil_03/_Ato2015-2018/2015/Lei/L13105.htm>. Acesso em 09. out. 2017.

. Supremo Tribunal Federal. SE 5206 AgR, Relator(a): Min. SEPÚLVEDA PERTENCE, Tribunal Pleno, julgado em 12/12/2001, DJ 30-04-2004 PP-00029 EMENT VOL-02149-06 PP-00958. 
Revista Eletrônica de Direito Processual - REDP.

Rio de Janeiro. Ano 12. Volume 19. Número 1. Janeiro a Abril de 2018

Periódico Quadrimestral da Pós-Graduação Stricto Sensu em Direito Processual da UERJ

Patrono: José Carlos Barbosa Moreira (in mem.). ISSN 1982-7636. pp. 83-106

www.redp.uerj.br

BRUNO, Susana. Conciliação: prática interdisciplinar e ferramentas para a satisfação do jurisdicionado. Belo Horizonte: Fórum, 2012.

BUENO, Cassio Scarpinella. Curso sistematizado de direito processual civil. Vol.1. $8^{\mathrm{a}}$ ed. rev. e atual. São Paulo: Saraiva, 2014.

CÂMARA, Alexandre Freitas. O novo processo civil brasileiro. São Paulo: Atlas, 2015.

CAMBI, Eduardo. Neoconstitucionalismo e neoprocessualismo. In: Panóptica, Vitória, ano 1, n. 6, fev. 2007, p. 1-44. Disponível em: 〈http: www.panoptica.org>. Acesso em 20. set. 2017.

- Neoconstitucionalismo e neoprocessualismo: direitos fundamentais, políticas públicas e protagonismo judiciário. São Paulo: Almedina, 2016.

CAMBI, Eduardo; FOGAÇA, Marcos Vargas. Direito Civil Constitucional. Revista de direito privado, vol. 61, jan.-mar. 2015.

CAMBI, Eduardo; PEREIRA, Fabricio Fracaroli. Estratégia nacional de prevenção e redução de litígios. Revista de processo, vol. 237, nov. 2014.

CAMBI, Eduardo; DOTTI, Rogéria; PINHEIRO, Paulo Eduardo d’Arce; MARTINS; KOZIKOSKI, Sandro Marcelo. Curso de Processo Civil Completo. São Paulo: RT, 2017.

CINTRA, Antonio Carlos de Araújo; GRINOVER, Ada Pellegrini; DINAMARCO, Cândido Rangel. Teoria Geral do Processo. $31^{\mathrm{a}}$ edição, revista e atualizada. São Paulo: Malheiros, 2015.

CONSELHO NACIONAL DE JUSTIÇA. Justiça restaurativa e constelações familiares avançam no Paraná. 04 maio 2017. Disponível em: < http://cnj.jus.br/noticias/judiciario/84704-justica-restaurativa-e-constelacoesfamiliares-avancam-no-parana>. Acesso em 24. Jun. 2017.

COSTA, Rafael Lançoni da. Reflexões sobre o Direito Processual Coletivo. In: Revista do Mestrado em Direito da Universidade Católica de Brasília RVMD. V. 6, nº 2, p. 269296, Jul-Dez, 2012.

DIDIER JÚNIOR, Fredie. Curso de direito processual civil: introdução ao direito processual civil, parte geral e processo de conhecimento. $17^{\mathrm{a}}$ ed. Salvador: Ed. Jus Podivm, 2015.

DINAMARCO, Cândido Rangel. A instrumentalidade do processo. $15^{\mathrm{a}}$ ed. São Paulo: 
Revista Eletrônica de Direito Processual - REDP.

Rio de Janeiro. Ano 12. Volume 19. Número 1. Janeiro a Abril de 2018

Periódico Quadrimestral da Pós-Graduação Stricto Sensu em Direito Processual da UERJ

Patrono: José Carlos Barbosa Moreira (in mem.). ISSN 1982-7636. pp. 83-106

www.redp.uerj.br

Malheiros, 2013.

DONIZETTI, Elpídio. Evolução (fases) do processualismo: sincretismo, autonomia, instrumentalismo e neoprocessualismo. 2012. Disponível em: < https://elpidiodonizetti.jusbrasil.com.br/artigos/121940209/evolucao-fases-doprocessualismo-sincretismo-autonomia-instrumentalismo-e-neoprocessualismo>.

Acesso em 10 out. 2017.

DUARTE, Écio Oto Ramos; POZZOLO, Susana. Neoconstitucionalismo e positivismo jurídico: as faces da teoria do direito em tempos de interpretação moral da constituição. São Paulo: Landy Editora, 2006.

FILIPPO, Thiago Baldani Gomes De. Neoconstitucionalismo e súmulas vinculantes. Porto Alegre: Sergio Antonio Fabris Ed., 2012.

GAJARDONI, Fernando da Fonseca. Teoria geral do processo: comentários ao CPC de 2015: parte geral. São Paulo: Forense, 2015.

HELLINGER, Bert. Ordens do Amor: um guia para o trabalho com constelações familiares. Tradução: Newton de Araújo Queiroz. São Paulo: Editora Cultrix, 2014.

JOBIM, Marco Félix. As Fases Metodológicas do Processo. Disponível em: <http://www.reajdd.com.br/artigos/ed8-7.pdf>. Acesso em 10. dez. 2017.

MINISTÉRIO PÚBLICO DO PARANÁ. MP-PR lança projeto "MP Restaurativo e a Cultura da Paz”. 07. abr. 2015. Disponível em: http://www.mppr.mp.br/modules/noticias/article.php?storyid=5238>. Acesso em 15. out. 2017.

MÖLLER, Max. Teoria Geral do neoconstitucionalismo: bases teóricas do constitucionalismo contemporâneo. Porto Alegre: Livraria do Advogado, 2011.

MOREIRA, José Carlos Barbosa. Efetividade do processo e técnica processual. Revista de processo, vol. 77, jan.-mar./1995, p. 877-888.

STORCH, Sami. Direito Sistêmico: primeiras experiências com constelações no judiciário.

In: Filosofia, Pensamento e Prática das Constelações Sistêmicas $-n^{o}$ 4. São Paulo: Conexão Sistêmica, 2015.

. Por que aprender Direito Sistêmico? 10 abril 2017. Disponível em: < https://direitosistemico.wordpress.com/2017/04/10/por-que-aprender-direitosistemico/>. Acesso em 25. set. 2017. 
Revista Eletrônica de Direito Processual - REDP.

Rio de Janeiro. Ano 12. Volume 19. Número 1. Janeiro a Abril de 2018

Periódico Quadrimestral da Pós-Graduação Stricto Sensu em Direito Processual da UERJ

Patrono: José Carlos Barbosa Moreira (in mem.). ISSN 1982-7636. pp. 83-106

www.redp.uerj.br

TARTUCE, Flávio. Impactos do novo CPC no Direito Civil. Rio de Janeiro: Forense; São

Paulo: Método, 2015.

TIVERON, Raquel. Justiça Restaurativa: a construção de um novo paradigma de justiça criminal. Brasília, DF: Thesaurus, 2014.

VASCONCELOS, Carlos Eduardo de. Mediação de conflitos e práticas restaurativas. $4^{\mathrm{a}}$ ed. rev., atual. e ampl. Rio de Janeiro: Forense; São Paulo: Método, 2015.

ZEHR, Howard. Justiça Restaurativa. Tradução Tônia Van Acker. São Paulo: Palas Athena, 2015. 